\title{
Synthesis, characterization and biological applications of mycosynthesized silver nanoparticles
}

\author{
Sathiyaseelan Anbazhagan ${ }^{1}$ Shajahan Azeez ${ }^{1} \cdot$ Girilal Morukattu $^{1} \cdot$ \\ Ramachandran Rajan $^{1} \cdot$ Kaviyarasan Venkatesan ${ }^{1}$. \\ Kalaichelvan Puthupalayam Thangavelu ${ }^{1}$
}

Received: 11 June 2017 / Accepted: 7 September 2017/Published online: 19 September 2017

(C) Springer-Verlag GmbH Germany 2017

\begin{abstract}
Silver nanoparticles (AgNPs) have been known for their inhibitory and bactericidal effects. In the present study, less toxic AgNPs using Cunninghamella echinulata is reported for the first time. The obtained AgNPs were characterized using UV-Visible spectrophotometer, XRD, FT-IR, FE-SEM with EDAX and HR-TEM. AgNPs showed the maximum absorbance at $420-430 \mathrm{~nm}$. The transmission electron micrograph revealed the formation of considerably uniform-sized AgNPs with an average size of $20-50 \mathrm{~nm}$. The reducing and capping agents responsible for AgNP synthesis were identified by FT-IR. AgNP-incorporated cotton fabrics exhibited promising antibacterial activity against pathogenic bacteria. In addition, the in vitro cell viability of Vero cells (African green monkey kidney cells) was analyzed and the $\mathrm{IC}_{50}$ value of AgNPs was found to be $62.8 \mu \mathrm{g} / \mathrm{mL}$. Taken together, these results clearly reveal less toxic AgNPs which could be exploited for various biomedical applications.
\end{abstract}

Keywords Cunninghamella echinulata $\cdot$ Silver nanoparticles - Cotton fabrics - Antibacterial activity . Cell viability

Electronic supplementary material The online version of this article (doi:10.1007/s13205-017-0961-9) contains supplementary material, which is available to authorized users.

Sathiyaseelan Anbazhagan

sathiyaseelan.bio@gmail.com

1 Nanobiotechnology Lab, Centre for Advanced Studies in Botany, University of Madras, Guindy Campus, Chennai 600025, India

\section{Introduction}

Biosynthesis of silver nanoparticles (AgNPs) became imperative in the field of nanomaterial development due to their increased antimicrobial properties with significant cost effectiveness (Yadav et al. 2015). AgNPs have been used in the field of medicine, water treatment, food processing and storage, pest control and in textile industries (Saravana Kumar et al. 2015). Silver is known as one of the oldest antimicrobial agents but lost its importance due to the emergence of various other antimicrobial agents including antibiotics (Balakumaran et al. 2016a). But today, in the scenario of emerging antibiotic-resistant pathogens, silver is regaining its importance as a potential antimicrobial agent in the form of AgNPs as it has unique ability to kill the pathogens. Silver nanopaticles exhibit broad spectrum antimicrobial activities against bacteria and fungi (Bhainsa and D'Souza 2006; Fayaz et al. 2009, 2010; Maliszewska et al. 2014).

There is always a growing demand to develop ecofriendly procedure for synthesis of nanoparticles that does not use toxic chemicals in the synthesis protocols. There has been a great interest in using biological systems as a tool for synthesis of new functional inorganic nanomaterials which are free from any kind of toxic chemicals and by-products. The use of biological systems for the synthesis of inorganic nanoparticles offers several advantages since the methods are easier to carry out and more economical than the others. Thus, various biological systems such as bacteria (Fayaz et al. 2010), fungi (Fayaz et al. 2009) and plants (Krishnaraj et al. 2010) are being continuously investigated for the synthesis of different kinds of metal nanoparticles.

The development of mycosynthesized AgNPs with an advantage in the field of nanotechnology (Fatima et al. 
2016), were reported in some fungi viz. Cladosporium cladosporioides (Balaji et al. 2009), Trichoderma viride (Fayaz et al. 2009), Alternaria alternata (Fr.) Keissler (MTCC-6572) (Gajbhiye et al. 2009), Penicillium purpurogenum NPMF (Nayak et al. 2011), Aspergillus ochraceus (Magdi et al. 2014), Neurospora intermedia (Hamedi et al. 2014), Penicillium nalgiovense AJ12 (Maliszewska et al. 2014), Schizophyllum commune (Arun et al. 2014), Aspergillus terreus (Thom) MTCC632 (Velhal et al. 2016) and Aspergillus flavus (KF934407) (Fatima et al. 2016). Although many fungi have been explored to synthesize metallic nanoparticles, the use of soil fungi for the synthesis of silver nanoparticles is still at its infancy. In the present study, AgNPs were synthesized using Cunninghamella echinulata which is being reported for the first time. The mycosynthesized AgNPs were characterized using spectral and microscopic techniques. Furthermore, AgNPs were coated onto the cotton fabrics and their antibacterial efficacy was evaluated. The cytotoxicity of AgNPs was also tested against Vero cell lines.

\section{Materials and methods}

\section{Materials}

Silver nitrate was purchased from Sigma-Aldrich, potato dextrose agar (PDA), Muller-Hinton agar (MHA) and 3-(4,5-dimethythiazol-2-yl)-2, 5-diphenyl tetrazolium bromide (MTT) were procured from HiMedia (Mumbai, India). Acridine orange and ethidium bromide were purchased from Sigma-Aldrich, USA.

\section{Isolation and identification of soil fungi}

The soil samples were collected from Indian Institute of Technology Madras, Chennai in depth from the surface soil and were kept in sterile polyethylene bags. The samples were then brought to the laboratory for isolation of soil fungi using serial dilution method (Saxena and Mehrotra 1952). Briefly, $10 \mathrm{~g}$ of soil sample was added into $100 \mathrm{~mL}$ of sterile distilled water and was serially diluted. The serially diluted fractions $\left(10^{-4}-10^{-6}\right)$ were cultured on potato dextrose agar (PDA) medium. After inoculation, the PDA plates were incubated at room temperature for 48-72 h. Totally, 24 soil fungi were isolated and identified using compendium of the soil fungi (Domsch et al. 1980). All the fungi were screened for the biological synthesis of silver nanoparticles.

\section{Synthesis of AgNPs}

The fungus $C$. echinulata was maintained in PDA slant at $25^{\circ} \mathrm{C}$. The fungus was then cultivated in $1 \mathrm{~L}$ of malt glucose yeast extract peptone (MGYP) broth medium (malt extract $5 \mathrm{~g}$, glucose $20 \mathrm{~g}$, yeast extract $1 \mathrm{~g}$ and peptone $5 \mathrm{~g}, \mathrm{pH} 6.5$ ) at $25-28{ }^{\circ} \mathrm{C}$ under static condition for $96 \mathrm{~h}$. After incubation, the mycelial mat was separated from the culture broth through filtration. The collected mycelial mat was washed thrice with sterile distilled water. About $10 \mathrm{~g}$ of the harvested mycelial mat was introduced in Erlenmeyer flask containing $100 \mathrm{~mL}$ of ultra pure water and kept under shaker at $120 \mathrm{rpm}$ for $48 \mathrm{~h}$. After incubation, the mycelial mat was discarded and the cell-free filtrate was collected by centrifugation at $8000 \mathrm{rpm}$ for $30 \mathrm{~min}$. A known volume of $\mathrm{AgNO}_{3}(10 \mathrm{mM})$ solution was added to the aqueous fungal extract and was incubated in the dark for $24 \mathrm{~h}$.

\section{Characterization of mycosynthesized AgNPs}

For preliminary confirmation, mycosynthesized AgNPs underwent spectral analysis for full scanning using UVVisible spectrophotometer (Hitachi-U 2900). X-ray diffraction (XRD) was recorded with $\mathrm{Cu} \mathrm{K} \alpha 1$ radiation at the scanning mode on a Burker AXS D8 X-ray diffractometer at $2 \theta$ ranged from $10^{\circ}$ to $80^{\circ}$. The FT-IR spectrum of the mycosynthesized AgNPs was recorded using PerkinElmer Fourier transform-infrared spectroscopy. The measurements were made in the range of $400-4000 \mathrm{~cm}^{-1}$ at a resolution of $4 \mathrm{~cm}^{-1}$. Transmission electron microscopy (TEM) analysis of AgNPs was carried out using FEITECNAI G2 T-30 S TWIN instrument.

\section{Prepration of AgNP-coated cotton fabrics}

The sterile cotton fabrics were cut into small rectangular pieces $(1 \times 1 \mathrm{~cm}$ diameter $)$, dried and were immersed in AgNP solution $(40 \mu \mathrm{g} / \mathrm{mL})$ for $30 \mathrm{~min}$. The fabrics were constantly agitated for $24 \mathrm{~h}$ at $120 \mathrm{rpm}$ using rotary shaker incubator at room temperature. The treated fabrics were dried at $40{ }^{\circ} \mathrm{C}$ for $30 \mathrm{~min}$ in a hot air oven. The surface morphology of AgNP-coated cotton fabrics was studied using field emission scanning electron microscope (Hitachi FESEM SU6600).

\section{Antibacterial activity of AgNP-coated cotton fabrics}

The bacteria Bacillus subtilis ATCC 55614, Staphylococcus aureus ATCC 29736, Escherichia coli ATCC 8739 and Klebsiella pneumoniae ATCC 13884 were obtained from the American Type Culture Collection (ATCC) centre. The synthesized AgNPs were tested for their potent antibacterial activity against Gram-positive (B. subtilis and S. aureus) and Gram-negative (E. coli and K. pneumoniae) bacteria by well-diffusion method (Balakumaran et al. 2016a). These bacteria were subcultured into the nutrient 
broth (NB) medium and incubated overnight. The bacterial cultures $\left(1 \times 10^{7}\right.$ cells $\left./ \mathrm{mL}\right)$ were swabbed on MullerHinton agar (MHA) plates and AgNP-immobilized cotton cloth was placed over the swabbed region and incubated overnight. After incubation, the zone of inhibition was measured in terms of millimeter. The experiment was repeated thrice.

\section{Cell viability assay}

MTT assay was performed using Vero cell line for analyzing the cytotoxicity of AgNPs. The cells were grown in Dulbecco's modified eagle's medium (DMEM) supplemented with $10 \%$ fetal bovine serum (FBS) and antibiotic penicillin $(100 \mu \mathrm{g} / \mathrm{mL})$ and streptomycin $(100 \mu \mathrm{g} / \mathrm{mL})$. $200 \mu \mathrm{L}$ of Vero cells at a density of $1 \times 10^{5}$ were placed in a 96-well plate. Then, the cells were incubated overnight at $37{ }^{\circ} \mathrm{C}$ in a humidified chamber with $5 \% \mathrm{CO}_{2}$ atmosphere and the media were discarded. Different concentrations of AgNPs and silver nitrate ranging from 10 to $100 \mu \mathrm{g} / \mathrm{mL}$ were added into each well of the plate and incubated for $24 \mathrm{~h}$. Finally, $20 \mu \mathrm{L}$ of MTT was added to each well and incubated for another $6 \mathrm{~h}$. After that, the medium was removed and $200 \mu \mathrm{L}$ of dimethyl sulfoxide (DMSO) was added to each well to dissolve the formazan. The absorbance was measured at $570 \mathrm{~nm}$ to calculate the percentage of cell viability. The assay was carried out in triplicate for reproducibility. $\mathrm{IC}_{50}$ concentration of $\mathrm{AgNPs}$ and $\mathrm{AgNO}_{3}$ were used to obsereve the apoptotic morphological features using acridine orange-ethidium bromide (AO-EB) dual staining and the images were observed through fluorescence microscope (FLoid cell imaging station).

\section{Statistical analysis}

All the quantitative data were expressed as mean \pm standard deviation. Statistical comparison was performed using one-way ANOVA with Prism software 6.00 (GraphPad software for windows, La Jolla, CA, USA). $P$ values of less than 0.05 were considered statistically significant.

\section{Results}

\section{Isolation and identification of soil fungus}

In this study, about 24 soil fungi were isolated and identified. Among them, 1 species belonged to the Coelomycetes, 4 species were of Zygomycetes and the remaining 19 were belonged to the Deuteromycetes. Among 24 fungi screened, only 1 isolate (VKAS01) was found to be best for the synthesis of silver nanoparticles (data not shown herein). This particular isolate was further identified as Cunninghamella echinulata (Thaxter) Thaxter through molecular characterization and its sequence data was submitted to the GenBank (Accession Number: KF170217).

\section{Synthesis and characterization of AgNPs}

In this study, the color of fungal culture filtrate was changed from pale yellow to dark brown after the addition of silver nitrate and the color change was observed within $24 \mathrm{~h}$ (Fig. 1a). However, silver nitrate retained the original color. The formation of AgNPs was further confirmed using UV-Vis spectrophotometer, which showed characteristic peak at $420-430 \mathrm{~nm}$. The absorbance of AgNPs was increased with the increase in incubation time as shown in Fig. 1b.

The crystalline nature of the mycosynthesized AgNPs was analyzed using XRD. The XRD analysis showed four clear bragg's peaks at $38.68^{\circ}, 46.1^{\circ}, 64.11^{\circ}$ and $77.4^{\circ}$ corresponding to (111) (200) (220) and (311) planes of the face-centered cubic (FCC) silver (Fig. 2a) and the data were matched well with the Joint Committee on powder diffraction standards (JCPDS) file No. 04-0783. The FT-IR spectrum of AgNPs depicted the presence of major bands at 1362, 1595, 1728 and $3432 \mathrm{~cm}^{-1}$ (Fig. 2b). The IR stretchings identified at $3432 \mathrm{~cm}^{-1}$ was corresponding to the $\mathrm{N}-\mathrm{H}$ stretching of primary amine, the band at $1595 \mathrm{~cm}^{-1}$ was corresponding to amide I variation, the band at $1728 \mathrm{~cm}^{-1}$ was the strong carbonyl $(\mathrm{C}=\mathrm{O})$ stretching and $1362 \mathrm{~cm}^{-1}$ was corresponding to the $\mathrm{C}-\mathrm{N}$ stretching of aromatic and aliphatic amines.

Field emission scanning electron microscopic image showed uniform-sized AgNPs (Fig. 3a) and the presence of silver was confirmed through FE-SEM with EDAX analysis (Fig. 3b). TEM micrograph showed the sphericalshaped AgNPs with a size of 20-50 nm (Fig. 3c, d).

\section{Characterization of AgNP-coated cotton fabrics}

Scanning electron micrograph of control cotton fabric showed smooth surface as shown in Fig. 4a. However, AgNP-coated cotton fabrics showed rough surface; in addition, presence of AgNPs was also seen on their surface (Fig. 4b, c).

\section{Antibacterial activity of AgNP-coated cotton fabrics}

In the present study, $C$. echinulata-mediated AgNPs showed excellent antibacterial activity against both Gram- 
Fig. 1 a Synthesis of silver nanoparticles; 1 - silver nitrate solution; 2-silver nanoparticles; b UV-Vis spectra of mycosynthesized silver nanoparticles at different time periods

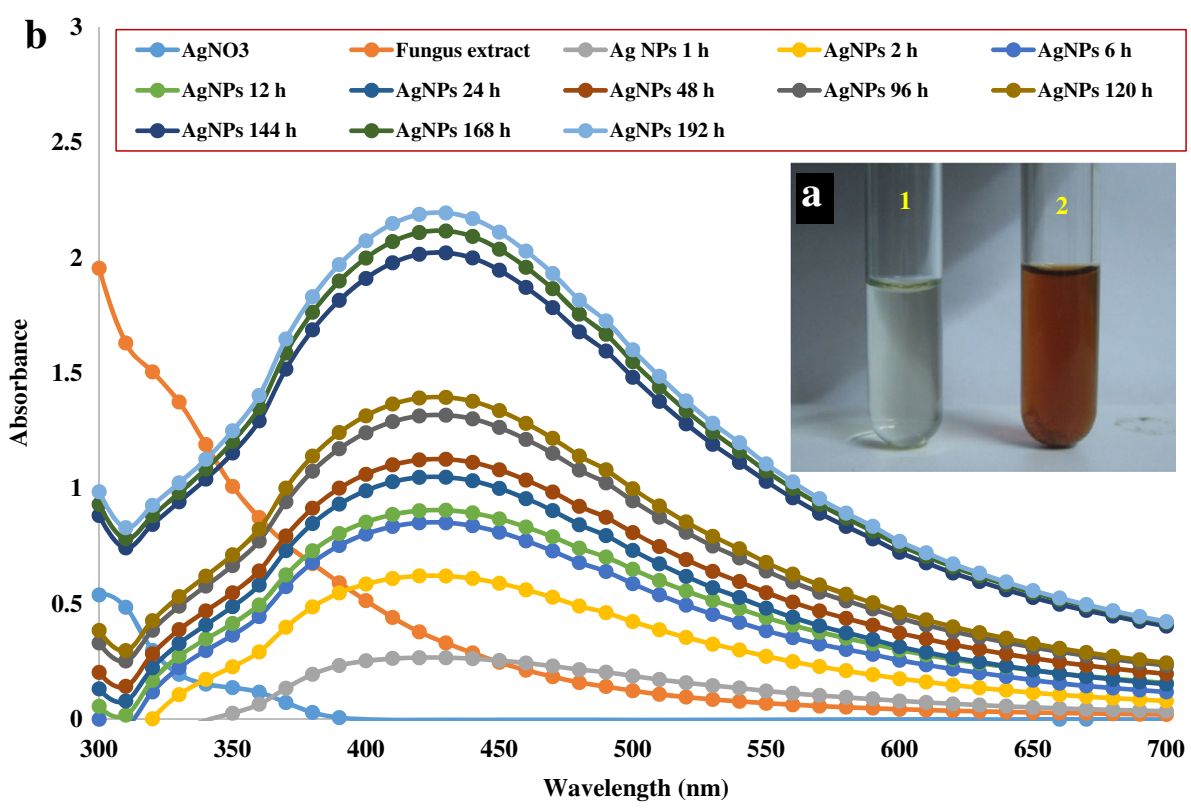

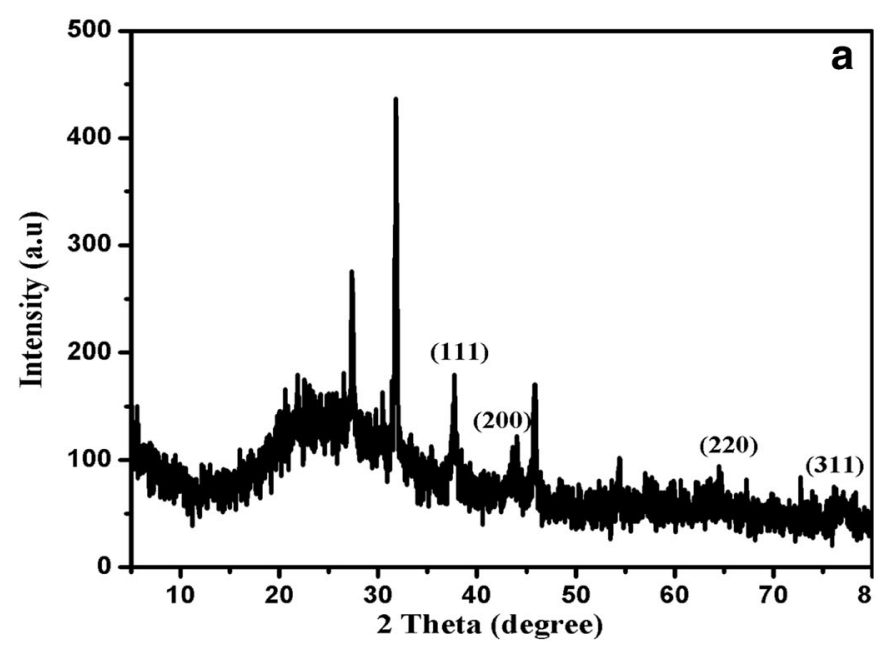

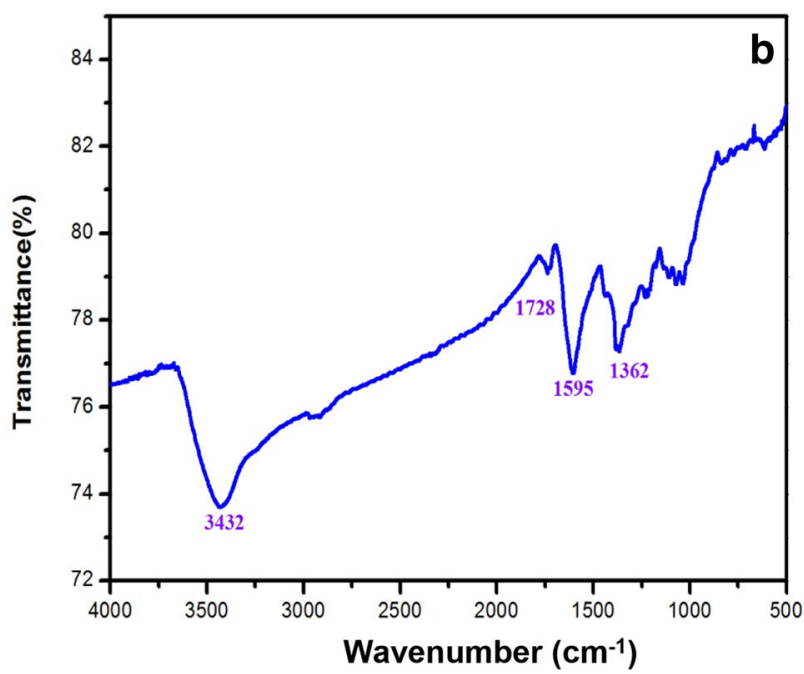

Fig. 2 a XRD spectrum of mycosynthesized silver nanoparticles; b FT-IR spectrum of mycosynthesized silver nanoparticles

positive and Gram-negative bacteria (Supplementary Figure 1 and Supplementary Table 1). Hence, the antibacterial activity of AgNP-coated cotton fabrics was performed and the data were presented in Fig. 5 and Table 1. The maximum antibacterial activity was recorded against $S$. aureus $(30 \mathrm{~mm})$ followed by $B$. subtilis $(27 \mathrm{~mm})$ and $E$. coli $(26 \mathrm{~mm})$; the lowest activity was observed against $K$. pneumoniae $(23 \mathrm{~mm})$.

\section{Cell viability}

In this study, the viability of Vero cells was found to be decreased with increasing concentrations of nanoparticles. The $\mathrm{IC}_{50}$ value of AgNPs was $62.8 \mu \mathrm{g} / \mathrm{mL}$ (Supplementary Figure 2). However, silver nitrate showed significant cytotoxicity against normal Vero cells. The apoptotic morphological features were studied using AO-EB double staining. The viable cells were light green in color, early apoptotic cells were observed in bright green in color because of the condensed chromatin, late apoptotic cells were orange in color and the nonviable cells were observed in red color (Fig. 6). On the contrary, silver nitrate-treated Vero cells showed more number of necrotic cells under AO-EB dual staining method as shown in Fig. 6. 

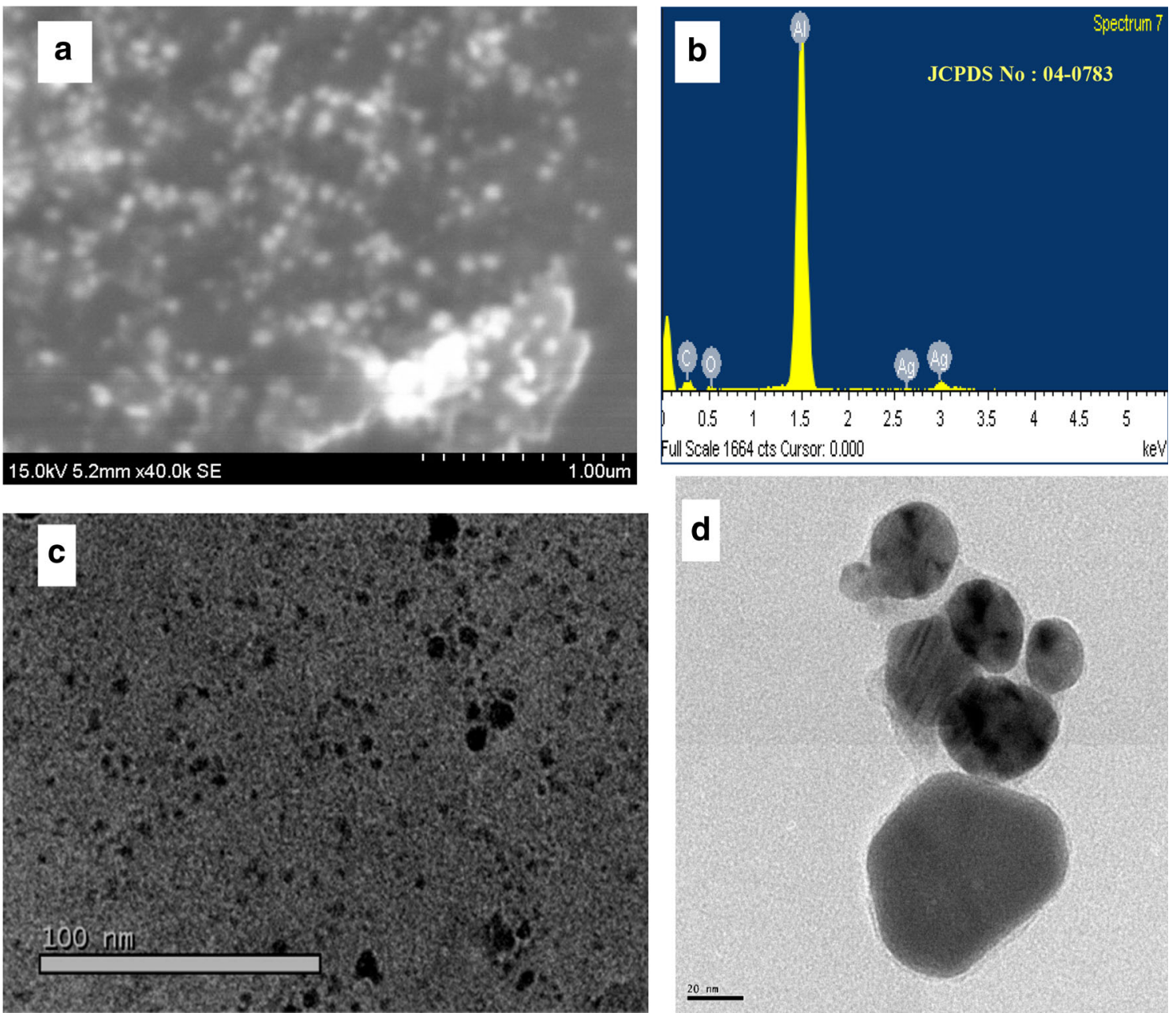

Fig. 3 a SEM micrograph of mycosynthesized silver nanoparticles; b EDAX spectrum of silver nanoparticles; c, d TEM micrographs of silver nanoparticles

\section{Discussion}

Soil fungi are often considered as the interesting sources for biological synthesis of nanoparticles (Azmath et al. 2016). To the best of our knowledge, C. echinulata, one of the soil fungi, has not been previously explored for the extracellular synthesis of metal nanoparticles. Hence, in this study, C. echinulata was taken for the synthesis of AgNPs (Supplementary Figure 3). Color change is the first indication for biological synthesis of AgNPs. The color of fungal culture filtrate was changed into dark brown after the addition of silver nitrate solution. The color change was probably due to the excitation of surface Plasmon resonance bands of the AgNPs (Hamedi et al. 2014). Interestingly, C. echinulata-mediated synthesis of AgNPs was observed within $24 \mathrm{~h}$.

Furthermore, the synthesis was confirmed using UV-Vis spectrophotometer, which showed characteristic peak at $420-430 \mathrm{~nm}$. Similar to our present study, other fungi have also shown peak at $420 \mathrm{~nm}$ for AgNP synthesis (Bhainsa and D'Souza, 2006; Fayaz et al. 2009). TEM image showed that $C$. echinulata-mediated AgNPs were found to be spherical in shape. In consistent with this result, other fungi have also synthesized spherical-shaped AgNPs (Azmath et al. 2016). The XRD analysis showed fcc silver and the data was well supported by JCPDS. Similarly, other researchers have also reported fcc silver using fungi (Gopinath et al. 2015; Balakumaran et al. 2016a). FT-IR analysis clearly revealed that the functional groups such as primary amine, amide-I, carbonyl, aliphatic and aromatic amines were believed to be involved in the fungus-mediated synthesis of AgNPs. Other studies have also supported this finding (Fayaz et al. 2010; Balakumaran et al. 2016a).

Many studies have clearly demonstrated that AgNPs inhibit bacterial enzymes and bind to DNA. Silver has been used effectively against different bacteria and fungi including antibiotic-resistant pathogens. Silver simultaneously attacks multiple sites within the cell to inactivate 

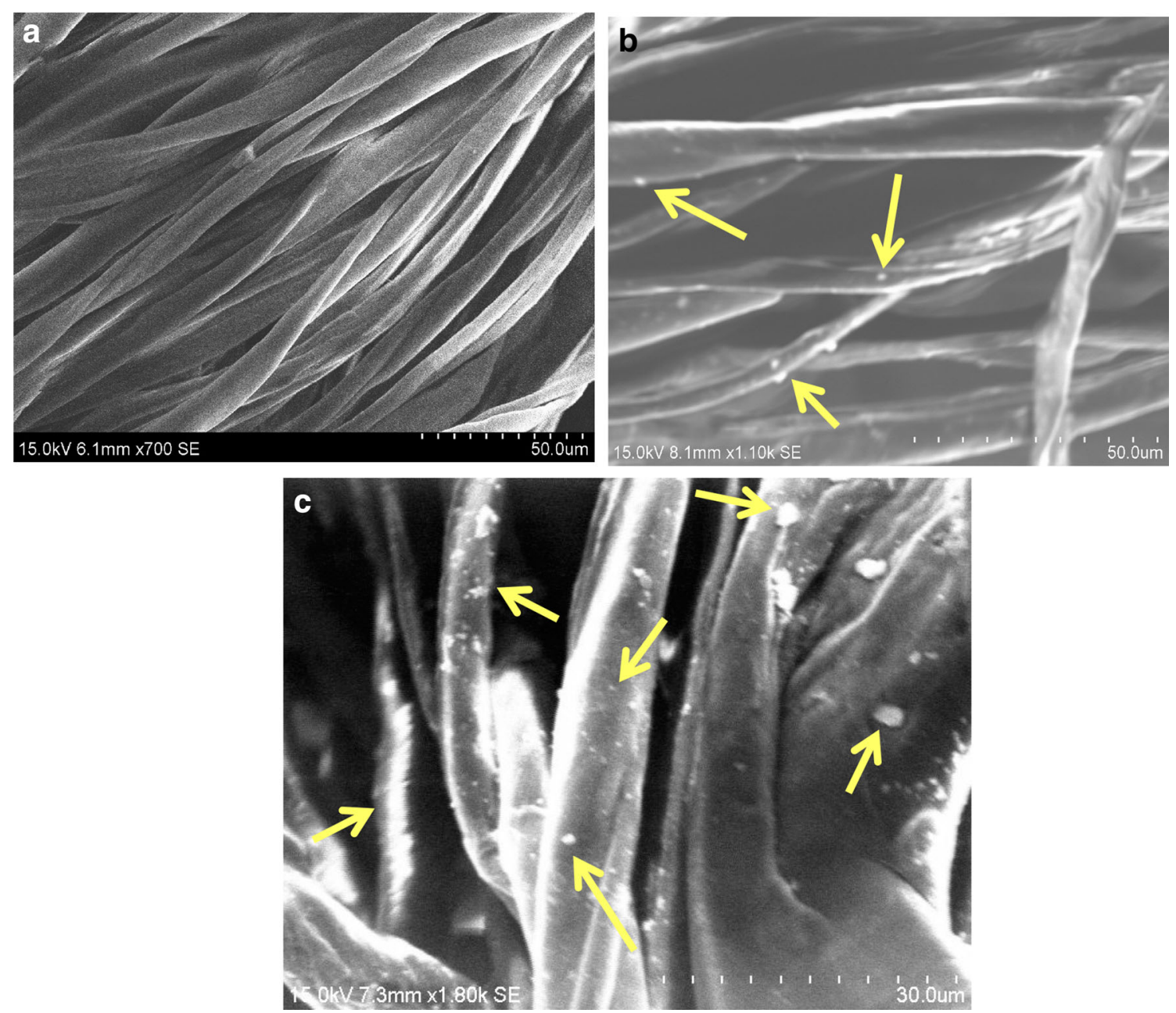

Fig. 4 Scanning electron microscopic images of untreated (control) cotton fabric (a) and AgNP-treated cotton fabric (b, c); arrows indicate AgNPs

critical physiological functions such as cell-wall synthesis, membrane transport, nucleic acid (such as RNA and DNA) synthesis, translation, protein folding and function and electron transport (Balakumaran et al. 2016a; Franci et al. 2015). In the previous study, $\mathrm{AgNO}_{3}$ showed more antibacterial property compared to AgNPs (Mosselhy et al. 2015). However, silver in its ionic form is more toxic when compared to silver as nanoparticle (Balakumaran et al. 2015). Since the final applications of the present study are to prepare human-less toxic and biocompatible materials, therefore, biogenic silver nanoparticles were preferred in this study. In an attempt to produce wound dressing materials for biomedical applications, AgNPs were coated onto the cotton fabrics and their antibacterial efficacy was evaluated. Interestingly, AgNP-coated cotton fabrics exhibited relatively good antibacterial activity against all the pathogens tested (Fig. 5). Similarly, few studies have also shown the antibacterial activity of AgNP-coated cotton fabrics (Zhang et al. 2014; Balakumaran et al. 2016b). Even MRSA bacterium was also found to be sensitive to AgNP-coated cotton fabric (Balakumaran et al. 2016b). Additionally, these fabrics have also shown excellent antibacterial activity after several wash cycles (Balakumaran et al. 2016b). The uniform-sized AgNPs were likely attached onto the cotton fabrics through electrostatic interaction or by physical adsorption. The formation of chemical bond between silver and the functional groups of cellulosic materials played a crucial role in the antibacterial activity and also in the durability of the AgNP-coated cotton fabrics (Perelshtein et al. 2008). Thus, these fabrics could be used for various medical purposes in the near future.

Cell viability or cell toxicity is the significant characteristic feature of the concentration of the drug. In the present study, the $\mathrm{IC}_{50}$ value was found to be $62.8 \mu \mathrm{g} / \mathrm{mL}$ against Vero cells. This result was found to be consistent 

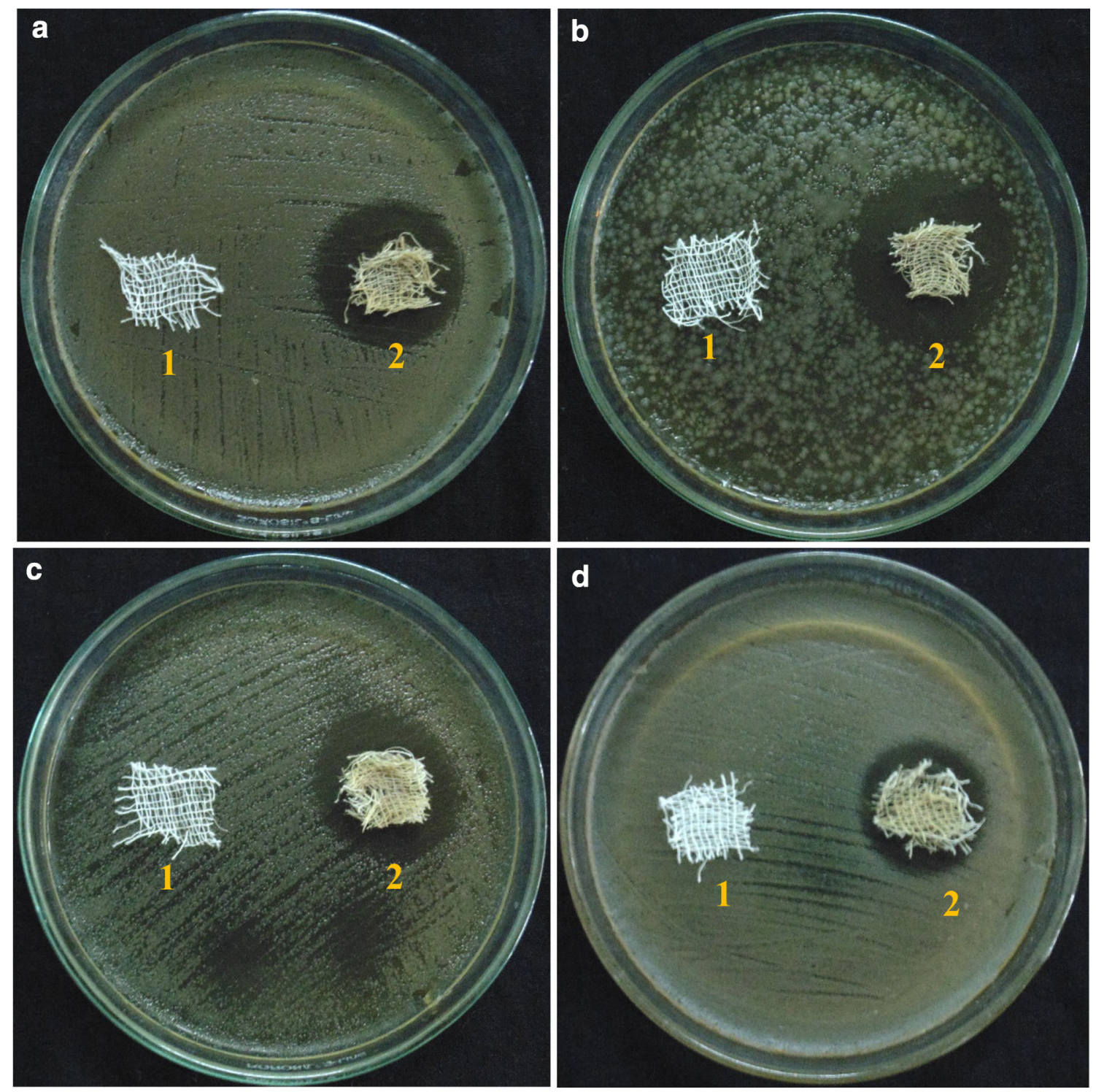

Fig. 5 Antibacterial activities of: (1) uncoated (control) fabric, (2) AgNP-coated fabric against, a B. subtilis; b S. aureus; c E. coli; d K. pneumoniae

Table 1 Antibacterial activity of mycosynthesized silver nanoparticle-coated cotton fabrics

\begin{tabular}{|c|c|c|c|c|}
\hline Name of the bacterium & Bacillus subtilis & Staphylococcus aureus & Escherichia coli & Klebsiella pneumoniae \\
\hline \multicolumn{5}{|l|}{ Zone of inhibition (mm) } \\
\hline Myco-AgNP-coated cotton fabric & $27 \pm 1.0$ & $30 \pm 1.8$ & $26 \pm 1.0$ & $23 \pm 1.6$ \\
\hline Cotton fabric & 0.0 & 0.0 & 0.0 & 0.0 \\
\hline
\end{tabular}

with the earlier study in which the $\mathrm{IC}_{50}$ value of AgNPs was $63.37 \mu \mathrm{g} / \mathrm{mL}$ (Balakumaran et al. 2015). Thus, it is obvious from this study that AgNPs, synthesized using $C$. echinulata, were less toxic and relatively safe; can be used for biomedical applications. Further, the mycosynthesis method employed in this study is greener, simple and low cost involvement and can be used for large scale production of nanoparticles.

\section{Conclusion}

In this study, biological silver nanoparticles were successfully synthesized using $C$. echinulata for the first time. The synthesized nanoparticles were coated onto the cotton fabrics and the fabrics showed significant antibacterial activity against selected human pathogenic bacteria. In addition, silver nanoparticles were found to be less toxic

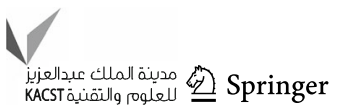




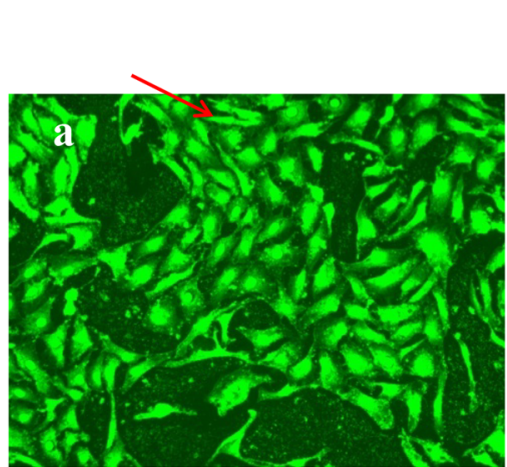

Control (Untreated)
Vero cells

AO-EB merged

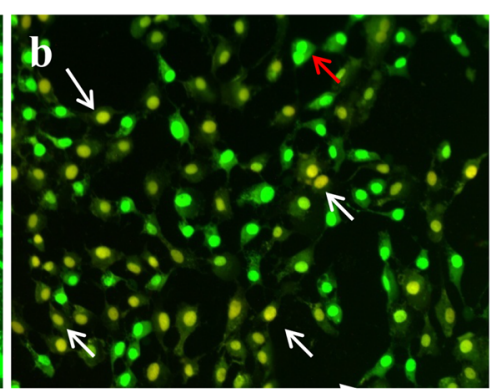

AgNPs treated

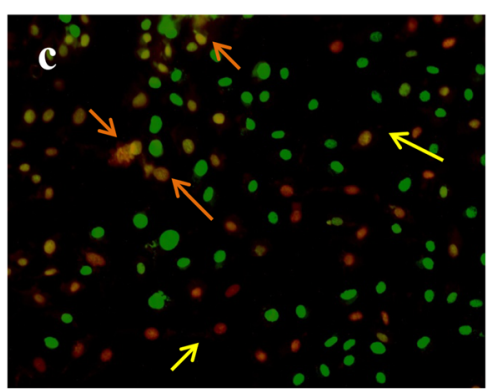

$\mathrm{AgNO}_{3}$ treated
Fig. 6 Fluorescent microscopic images of Vero cells after AO-EB dual staining. a Control cells; b silver nanoparticle-treated cells; c silver nitrate-treated cells. The viable cells are (light green) indicated by red arrows; early apoptotic cells (bright green to yellow)

against normal Vero cells. Based on these positive outcomes, it is possible to use biological AgNPs to develop low cost bandages for wound dressing.

Acknowledgements The author thanks the University Grants Commission (UGC), New Delhi, India for providing research fellowship under UGC-BSR scheme. We are also grateful to the Director, CAS in Botany, University of Madras for providing laboratory facilities. The authors are thankful to the Director, National Centre for Nanoscience and Nanotechnology (NCNSNT), University of Madras for electron microscopic facilities.

\section{Compliance with ethical standards}

Conflict of interest All authors declare that there are no conflict of interest.

\section{References}

Arun G, Eyini M, Gunasekaran P (2014) Green synthesis of silver nanoparticles using the mushroom fungus Schizophyllum commune and its biomedical applications. Biotechnol Bioprocess Eng 19:1083-1090

Azmath P, Baker S, Rakshith D, Satish S (2016) Mycosynthesis of silver nanoparticles bearing antibacterial activity. Saudi Pharm J 24:140-146

Balaji DS, Basavaraja S, Deshpande R, Mahesh DB, Prabhakar BK, Venkataraman A (2009) Extracellular biosynthesis of functionalized silver nanoparticles by strains of Cladosporium cladosporioides fungus. Colloids Surf B Biointerfaces 68:88-92

Balakumaran MD, Ramachandran R, Kalaichelvan PT (2015) Exploitation of endophytic fungus, Guignardia mangiferae for extracellular synthesis of silver nanoparticles and their in vitro biological activities. Microbiol Res 178:9-17

Balakumaran MD, Ramachandran R, Balashanmugam P, Mukeshkumar DJ, Kalaichelvan PT (2016a) Mycosynthesis of silver and gold nanoparticles: optimization, characterization and antimicrobial activity against human pathogens. Microbiol Res 182:8-20

Balakumaran MD, Ramachandran R, Jagadeeswari S, Kalaichelvan PT (2016b) In vitro biological properties and characterization of are indicated by white arrows; late apoptotic cells (orange) are indicated by orange arrows and necrotic cells (red) are indicated by yellow arrows

nanosilver coated cotton fabrics-an application for antimicrobial textile finishing. Int Biodeterior Biodegrad 107:48-55

Bhainsa KC, D'Souza SF (2006) Extracellular biosynthesis of silver nanoparticles using the fungus Aspergillus fumigatus. Colloids Surf B Biointerfaces 47:160-164

Domsch KH, Gams W, Anderson T (1980) Compendium of Soil Fungi, vol 1. Academic Press, London, pp 1-860

Fatima F, Verma SR, Pathak N, Bajpai P (2016) Extracellular mycosynthesis of silver nanoparticles and their microbicidal activity. J Glob Antimicrob Resist 7:88-92

Fayaz AM, Balaji K, Kalaichelvan PT, Venkatesan R (2009) Fungal based synthesis of silver nanoparticles - an effect of temperature on the size of particles. Colloids Surf B Biointerfaces 74:123-126

Fayaz AM, Balaji K, Girilal M, Yadav R, Kalaichelvan PT, Venketesan R (2010) Biogenic synthesis of silver nanoparticles and their synergistic effect with antibiotics: a study against gram-positive and gram-negative bacteria. Nanomed 6:103-109

Franci G, Falanga A, Galdiero S, Palomba L, Rai M, Morelli G, Galdiero M (2015) Silver nanoparticles as potential antibacterial agents. Molecules 20:8856-8874

Gajbhiye M, Kesharwani J, Ingle A, Gade A, Rai M (2009) Fungusmediated synthesis of silver nanoparticles and their activity against pathogenic fungi in combination with fluconazole. Nanomed 5:382-386

Gopinath PM, Narchonai G, Dhanasekaran D, Ranjani A, Thajuddin $\mathrm{N}$ (2015) Mycosynthesis, characterization and antibacterial properties of AgNPs against multidrug resistant (MDR) bacterial pathogens of female infertility cases. Asian J Pharm Sci 10:138-145

Hamedi S, Shojaosadati SA, Shokrollahzadeh S, Hashemi-Najafabadi S (2014) Extracellular biosynthesis of silver nanoparticles using a novel and non-pathogenic fungus, Neurospora intermedia: controlled synthesis and antibacterial activity. World J Microbiol Biotechnol 30:693-704

Krishnaraj C, Jagan EG, Rajasekar S, Selvakumar P, Kalaichelvan PT, Mohan N (2010) Synthesis of silver nanoparticles using Acalypha indica leaf extracts and its antibacterial activity against water borne pathogens. Colloids Surf B Biointerfaces 76:50-56

Magdi HM, Mourad MHE, El-Aziz MMA (2014) Biosynthesis of silver nanoparticles using fungi and biological evaluation of mycosynthesized silver nanoparticles. Egypt J Exp Biol (Bot) 10:1-12 
Maliszewska I, Juraszek A, Bielska K (2014) Green synthesis and characterization of silver nanoparticles using ascomycota fungi Penicillium nalgiovense AJ12. J Clust Sci 25:989-1004

Mosselhy DA, El-Aziz MA, Hanna M, Ahmed MA, Husien MM, Feng Q (2015) Comparative synthesis and antimicrobial action of silver nanoparticles and silver nitrate. J Nanopart Res 17:473

Nayak RR, Pradhan N, Behera D, Pradhan KM, Mishra S, Sukla LB, Mishra BK (2011) Green synthesis of silver nanoparticle by Penicillium purpurogenum NPMF: the process and optimization. J Nanoparticle Res 13:3129-3137

Perelshtein I, Applerot G, Perkas N, Guibert G, Mikhailov S, Gedanken A (2008) Sonochemical coating of silver nanoparticles on textile fabrics (nylon, polyester and cotton) and their antibacterial activity. Nanotechnology 19:245705

Saravana Kumar P, Balachandran C, Duraipandiyan V, Ramasamy D, Ignacimuthu S, Al-Dhabi NA (2015) Extracellular biosynthesis of silver nanoparticle using Streptomyces sp. 09 PBT 005 and its antibacterial and cytotoxic properties. Appl. Nanosci 5:169-180 Saxena R, Mehrotra BS (1952) Fungus flora of Allahabad soil. Proc nat Acad India 22:22-43

Velhal SG, Kulkarni SD, Latpate RV (2016) Fungal mediated silver nanoparticle synthesis using robust experimental design and its application in cotton fabric. Int Nano Lett 6:257-264

Yadav A, Kon K, Kratosova G, Duran N, Ingle AP, Rai M (2015) Fungi as an efficient mycosystem for the synthesis of metal nanoparticles: progress and key aspects of research. Biotechnol Lett 37:2099-2120

Zhang G, Liu Y, Gao X, Chen Y (2014) Synthesis of silver nanoparticles and antibacterial property of silk fabrics treated by silver nanoparticles. Nanoscale Res Lett 9:216 